\section{A. ARS BILDUMA \\ ISSN 1989-9262 \\ UPV/EHU Press}

ARSBILDUMA (CC BY-NC-ND 4.0)

https://doi.org/10.1387/ars-bilduma.19777

BIBLID [(2019), 9; 17-32]

Recibido: 22/05/2018 Aceptado: 25/09/2018

\section{MARÍA JOSEFA TARIFA CASTILLA}

Universidad de Zaragoza

Departamento de Historia del Arte

Facultad de Filosofía y Letras

c/ San Juan Bosco, 7

50009, Zaragoza (Zaragoza)

mjtarifa@unizar.es

ORCID: https://orcid.org/0000-0001-7723-2238

Miembro del Grupo de Investigación de Referencia Vestigium, financiado por el Gobierno de Aragón (H19_17R), y cofinanciado por el Programa operativo Feder Aragón 2014-2020 "Construyendo Europa desde Aragón".

El estudio ha sido realizado en el marco de los Proyectos de Investigación I+D "Los diseños de arquitectura en la Península Ibérica entre los siglos XV y XVI. Inventario y Catalogación" (HAR2014-54281-P) y "Los diseños de arquitectura de tradición gótica en la Península Ibérica entre los siglos XVII y XVIII. Inventario y Catalogación" (HAR 2017-85523-P).

\title{
UNA TRAZA DE LA IGLESIA GÓTICA DE SANTA MARÍA DE SAN SEBASTIÁN (GIPUZKOA) DE 1539
}

\author{
THE DESIGN OF THE CHURCH OF SAINT MARY OF SAINT SEBASTIAN \\ (GIPUZKOA) OF 1539
}

\author{
LE PLAN DE L'ÉGLISE DE LA SAINTE-MARIE DU SAINT-SÉBASTIEN (GIPUZKOA) \\ DE 1539
}

\section{RESUMEN}

El artículo da a conocer una traza de la iglesia de Santa María de San Sebastián conservada en el Archivo Histórico Provincial de Zaragoza, con la planta de templo gótico existente en 1539 y la capilla que Alonso de Idiáquez, secretario del emperador Carlos V y su esposa solicitaron construir próxima al presbiterio. El estudio también proporciona datos inéditos de la ampliación del edificio por la cabecera a fines del Quinientos, fruto de la consulta del Archivo Diocesano de Pamplona.

\section{PALABRAS CLAVE}

Diseños de arquitectura; arquitectura religiosa; siglo XVI; San Sebastián (Gipuzkoa); Alonso de Idiáquez; Juan de Lizarazu; Nicolás de Lizarraga; Juan de Anzarobe.

\section{ABSTRACT}

The article reveals the drawing of the church of Saint Mary of Saint Sebastian preserved in the Provincial Historical Archive of Saragossa, with the existing Gothic temple plant in 1539 and the new patronage chapel that Alonso de Idiáquez, secretary of Carlos V and his wife requested to build next to the major altar. The study provides unpublished information of the extension undertaken in the apse in the sixteenth century, extracted from the consultation of the Diocesan Archive of Pamplona.

\section{KEYWORDS}

Architectural designs; religious architecture; XVI century; Saint Sebastian (Gipuzkoa); Alonso de Idiáquez; Juan de Lizarazu; Nicolás de Lizarraga; Juan de Anzarobe.

\section{RÉSUMÉ}

L'article permet de connaitre le plan de l'église de la Sainte-Marie du SaintSébastien conservé dans le Fichier Historique Provincial de Saragosse, avec la plante du temple gothique existant en 1539 et la nouvelle chapelle du patronat que Alonso de Idiáquez, secrétaire de l'empereur Charles $\mathrm{V}$ et son épouse ont sollicité construire proche du plus grand autel. L'étude fournit aussi des données inédites de l'agrandissement attaqué dans l'édifice par le chevet à partir du dernier tiers du XVI ${ }^{\mathrm{e}}$ siècle.

\section{MOTS-CLÉS}

Designs d'architecture; architecture des églises; Saint-Sébastien (Gipuzkoa); Alonso de Idiáquez; Juan de Lizarazu; Nicolás de Lizarraga; Juan de Anzarobe. 


\section{INTRODUCCIÓN}

La actual iglesia de Santa María de San Sebastián fue erigida de nueva planta entre 1743 y 1774 en el estilo barroco imperante en aquella centuria a tenor de los proyectos elaborados por distintos maestros, como José de Lizardi (1741), Pedro Ignacio de Lizardi e Ignacio de Ibero (1742) y gracias a la financiación en gran parte de la Real Compañía Guipuzcoana de Caracas, además de la contribución del regimiento de la ciudad, como refieren las diversas publicaciones centradas en su estudio (fig. 1) ${ }^{1}$.

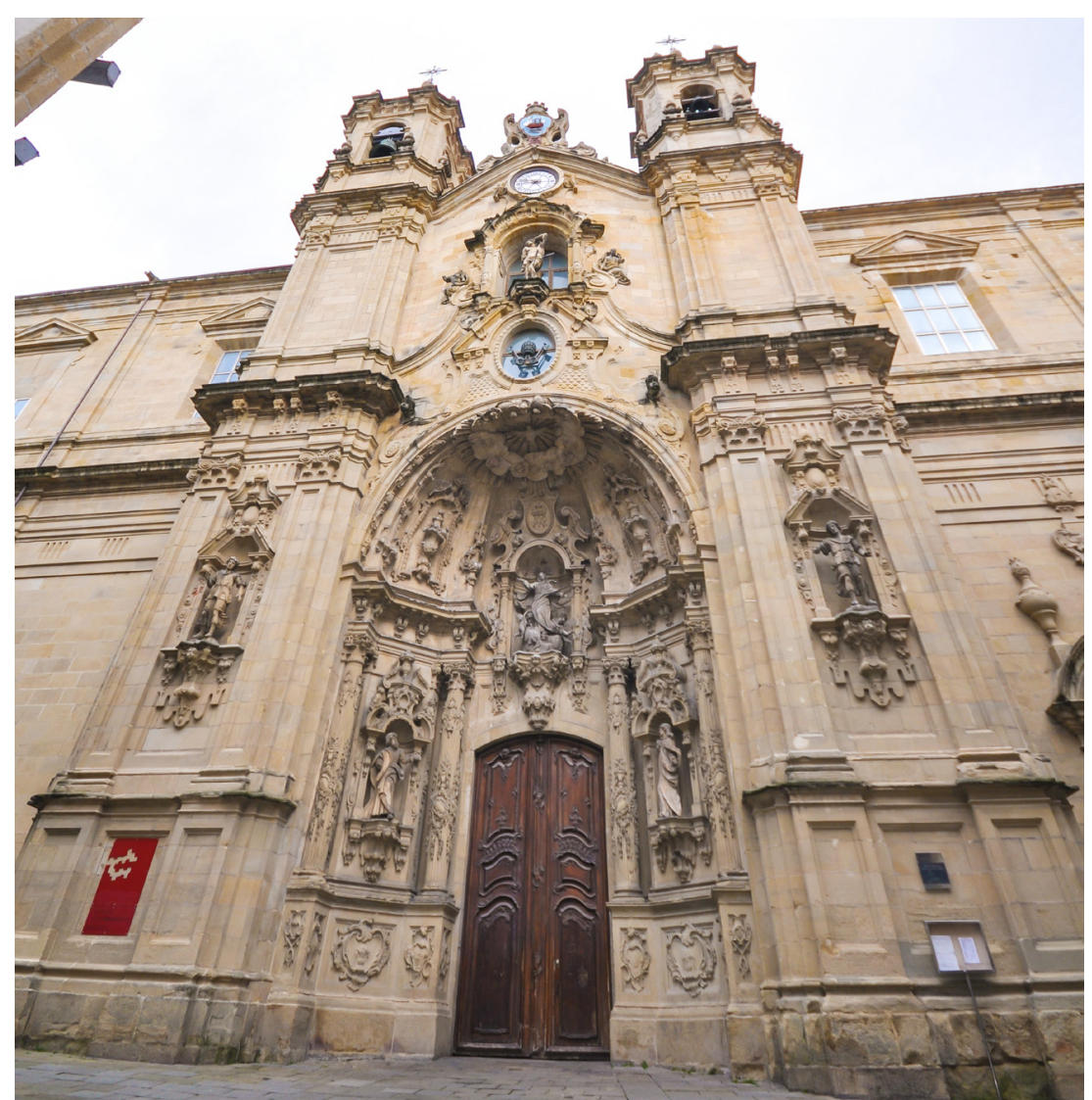

Fig. 1: Exterior de la iglesia de Santa María de San Sebastián
Un edificio de planta de salón rectangular de tres naves, más ancha la central que las laterales, articuladas por seis grandes pilares octogonales en cuatro tramos, que tienen su correspondencia con otros tantos pilares adosados a los muros perimetrales, disponiéndose un coro en alto a los pies y la entrada principal en el segundo tramo de la nave de la epístola, flanqueada por dos torres cuadradas. Las naves se cubren a la misma altura con bóvedas nervadas de crucería con terceletes o diseños estrellados más complejos en los tramos que preceden el presbiterio, además de una cúpula sobre pechinas que voltea el espacio central del crucero y una bóveda de cuarto de esfera sobre el ábside semicircular, delimitado por la sacristía y dependencias secundarias (fig. 2).

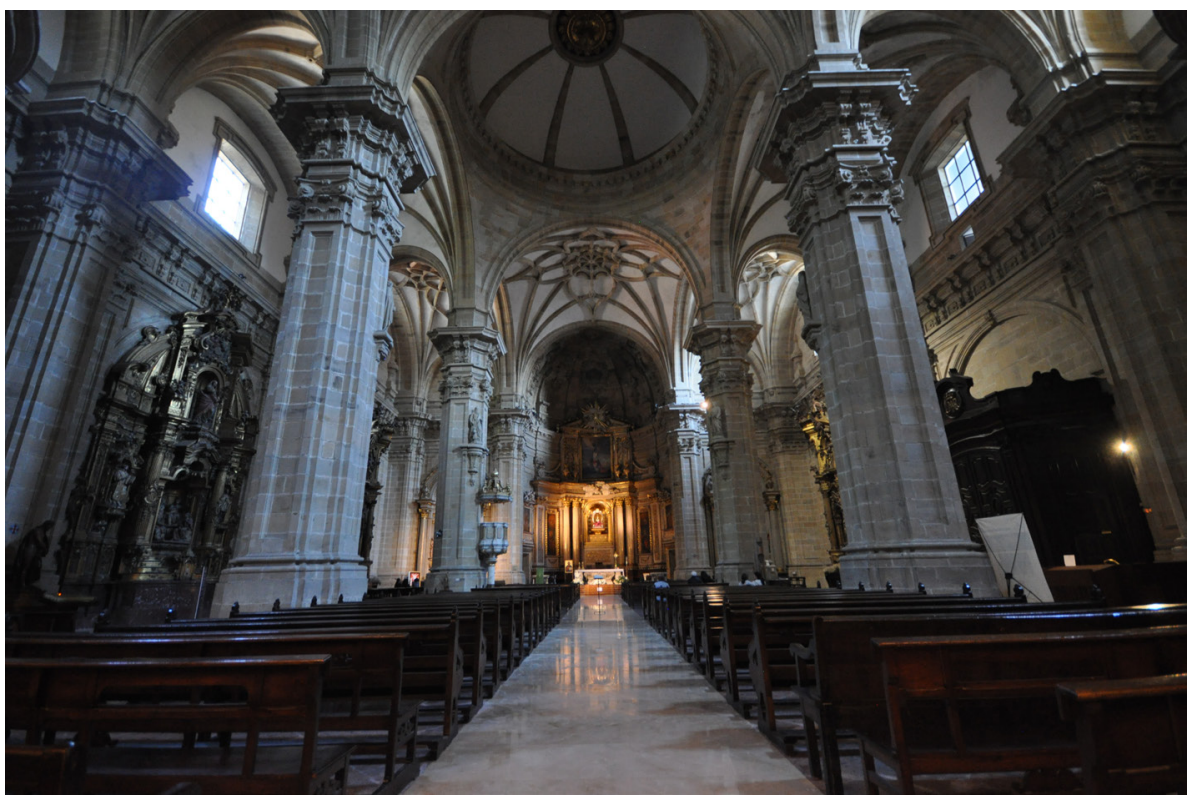

Fig. 2: Interior de la iglesia de Santa María de San Sebastián

MURUGARREN, L: Basílica de Santo María San Sebastión Su historia arte y vida San Sebastián, Caja de Ahorros Municipal, 1973. PEÑUELAS, J. "La iglesia de Santa María de San Sebastián" Boletín de estudios históricos sobre San Sebastián, n. ${ }^{\circ}$ 7, 1973, pp. 291-298. CORTÁZAR Y MACHIMBARRENA, A.: Monografía de la Iglesia Parroquial de Santa María, de la ciudad de San Sebastián. San Sebastián, Grupo Dr. Camino de Historia Donostiarra, 1974. ÁLVAREZ OSES, J. A.: "A propósito de un pleito surgido en la construcción de la Parroquia de Santa María (1775-1756)", Boletín de estudios históricos sobre San 
Sin embargo, todavía en la actualidad hay un gran desconocimiento sobre el templo anterior construido en distintas fases a lo largo de la época medieval y emplazado en el mismo solar que el actual, en la ladera del monte Urgull, en dirección perpendicular al eje de la calle Mayor y con el ábside en la terminación de la calle 31 de Agosto, lo que obligó a disponer la portada principal de acceso en el lateral sur del edificio. Con objeto de solventar parte de la laguna histórico-artística referente a esta iglesia de Santa María, el presente artículo revela la planimetría del edificio gótico existente en 1539 a través del estudio de una traza y documentación localizados en el Archivo Histórico Provincial de Zaragoza, generados con motivo del interés por parte de los nobles guipuzcoanos Alonso de Idiáquez y su mujer Gracia de Olazábal de erigir una capilla de patronato con fines funerarios. A esta información relativa al templo mariano donostiarra anterior a la reforma dieciochesca, se suman otros datos alusivos a la ampliación acometida en el mismo por el espacio de la cabecera a partir del último tercio del siglo XVI obtenidos de la consulta del Archivo Diocesano de Pamplona, ya que San Sebastián dependió eclesiásticamente a lo largo de la Edad Media y Moderna del obispado pamplonés.

\section{LA IGLESIA GÓTICA DE SANTA MARÍA DE SAN SEBASTIÁN EN LA} PRIMERA MITAD DEL QUINIENTOS

A comienzos del siglo XVI la iglesia gótica de Santa María era uno de los edificios de culto más importantes existentes en San Sebastián, junto con la parroquia de San Vicente ${ }^{2}$ Escenario principal de los actos religiosos desarrollados en la localidad donostiarra, en este templo tenía lugar la visita del Santo Oficio de la Inquisición, la jura de los monarcas y alcaldes y la celebración de los funerales de los reyes. Igualmente, a esta parroquia acudía

Sebastián, n. 9 9, 1975, pp. 185-207. CORMENZANA LIZARRÍBAR, I.: "El arte de la Basílica de Santa María del Coro en San Sebastián", Boletín de estudios históricos sobre San Sebastián, n. 9, 1975, pp 271-298. VVAA: “Iglesia de Santa María en Donostia-San Sebastián”, en MUÑOZ-BAROJA PEÑAGA RICANO, J. (coord.), Monumentos Nacionales de Euskadi, tomo II, Guipúzcoa. Vitoria, Gobierno Vasco Departamento de Cultura, 1985, pp. 91-102. ASTIAZARAIN ACHABAL, M. I.: Arquitectos guipuzcoanos del siglo XVIII. Martín de Zaldúa, José de Lizardi, Sebastián de Lecuona. San Sebastián, Diputación Foral de Guipúzco 1988, pp. 59, 61-62, 245, 248-252. ASTIAZAR ÁIN ACHABAL, M. Is La

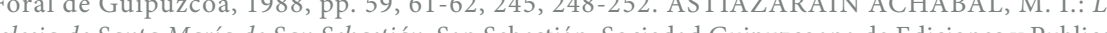
iglesia de Santa María de San Sebastián. San Sebastian, Sociedad Guipuzcoana de Ediciones y Publicaciones, 1989

TARIFA CASTILLA, M. J., "La iglesia de San Vicente en San Sebastián: los contratos, trazas y artífices del proyecto edilicio (1507-1548)", Locus Amoenus, n. ${ }^{0} 16,2018$, pp. 71-92. en primer lugar el obispo de Pamplona cuando efectuaba la visita pastoral en la villa, -ya que hasta 1852 San Sebastián, al igual que gran parte de los territorios guipuzcoanos, perteneció desde el punto de vista de la jurisdicción eclesiástica a la diócesis pamplonesa ${ }^{3}$-, y en las procesiones sus cruces desfilaban las últimas dada su antigüedad, acompañadas de la imagen de Nuestra Señora del Coro. Incluso algunos de los acontecimientos históricos más relevantes vividos por los donostiarras en la primera mitad del Quinientos se sucedieron en este marco arquitectónico incomparable, como aconteció a comienzos de la década de 1520, cuando gran parte del vecindario se reunió en el interior del templo para discutir la postura política que se debía adoptar ante la revuelta comunera, jurando, ante la exposición del Santísimo Sacramento, permanecer fieles al monarca Carlos I, lealtad que fue compensada a la villa en 1522 con el título de Noble y Leal ${ }^{4}$.

El templo gótico se había erigido sobre el solar de otra iglesia medieval románica de tres naves estrechas, abovedada y con pilares, manteniendo, por tanto, en planta el mismo esquema. Camino y Orella refiere a fines de la década de 1780, cuando ya había sido edificada la nueva iglesia barroca, que "su fabrica anterior fue una excelente pieza del gusto que llaman gótico, y tenía mucha semejanza de la parroquia de Santiago de Bilbao en sus corredores y tribunas excavadas en la pared, que rodeaban la iglesia, y también con la de San Salvador de Guetaria, uno de los más primorosos templos que hay en Guipúzcoa, aunque menor que la de Santa María la antigua. Esta, según el aire de arquitectura, debía ser del siglo XII o XIV, de que son también las catedrales ejecutadas según aquel gusto, como la de Burgos y otras" ${ }^{\prime \prime}$. Por tanto, según la descripción de este cronista donostiarra, la iglesia gótica de Santa María contaba en alzado con un triforio dispuesto sobre las arcadas de comunicación con las naves laterales, según se puede seguir apreciando hoy en la catedral de Santiago de

3 GOÑI GAZTAMBIDE, J.: Historia de los obispos de Pamplona, I. Siglos IV-XIII. Pamplona, Eunsa, 1979, pp. 288-290 y 448-449. GOÑI GAZTAMBIDE, J.: “Diócesis de Pamplona”, Príncipe de Viana, Homenaje a José Goñi Gaztambide, n. ${ }^{\circ} 245,2008$, p. 547.

4 CAMINO Y ORELLA, J.: Historia civil, diplomático, eclesiástica anciana y moderna de la ciudad de San Sebastián, con varias noticias particulares pertenecientes a la provincia de Guipúzcoa. San Sebastián, Ediciones del Ayuntamiento de San Sebastián, 1963, p. 93. Sobre esta revuelta y su incidencia en Guipúzcoa, véase AZCONA, T. DE: San Sebastián y la provincia de Guipúzcoa durante la Guerra de las Comunidades (1520-1521): Estudio y documentos. San Sebastián, Grupo Doctor Camino de Historia de San Sebastián, 1974. IMİZCOZ, J. M.: "Hacia nuevos horizontes", en ARTOLA, M. (ed.), Historia de Donostia-San Sebastián. San Sebastián. Editorial Nerea, 2000, p. 106.

5 MURUGARREN, L.: op. cit., pp. 13-17. IZAGUIRRE, R. DE: "Las sucesivas edificaciones de Santa María la Mayor", Boletín de estudios históricos sobre San Sebastián, n. ${ }^{\circ}$ 7, 1973, pp. 299-300. CAMINO Y ORELLA, J.: op. cit., p. 174. 
Bilbao, el templo gótico más monumental de Bizkaia, comenzado a fines del siglo XIV, de tres naves, mayor la central que las laterales, articuladas por cuatro tramos sustentados por pilares de sección circular a los que se adosan columnillas de basas escalonadas, crucero alineado y girola tras la capilla mayor ${ }^{6}$. Un triforio que también presenta la iglesia guipuzcoana de San Salvador de Getaria (siglos XIV-XV), un edificio gótico de tres naves articuladas en tres tramos, separadas por pilares cilíndricos con columnillas adosadas, sobre las que se voltean bóvedas de crucería y terceletes ${ }^{7}$.

De acuerdo con los datos proporcionados por Murugarren, el templo gótico de Santa María de San Sebastián disponía en 1540 de doce altares: el mayor, con su retablo formado por imágenes escultóricas (1523); el de San Juan Bautista con un retablo de 1516; el de San Pedro, junto al altar mayor y en el que hacía sus cultos la cofradía de pescadores; el de San Simón y San Judas; el de San Matías; el de San Bernabé; el de Nuestra Señora de Burdeos o del Rosario; el de Nuestra Señora la Vieja, luego denominada del Socorro o la Morena; el de San Lucas; el de Santo Tomás y el de la Santa Cruz. La iglesia contaba además con un claustro en el que se rendía culto a Santa Marta, con una capilla en su centro dedicada a ella, Santa Catalina, San Sebastián, en la que la familia Engómez tenía esculpidas sus armas, San Jorge, San Esteban y Santa Úrsula ${ }^{8}$.

Tal y como se dibuja en el plano de San Sebastián y su recinto amurallado de 1552 conservado en el Archivo General de Simancas', del que se conserva una copia en el archivo cartográfico del Servicio Histórico Militar ${ }^{10}$, la iglesia de Santa María se emplazaba a los pies de la falda del monte Urgull, en dirección perpendicular al eje de la rúa mayor y en la

6 VVAA: "Iglesia de Santiago en Bilbao", en MUÑOZ-BAROJA PEÑAGARICANO, J. (coord.), Monu mentos Nacionales de Euskadi, tomo III. Vizcaya. Vitoria, Gobierno Vasco, Departamento de Cultura, 1985, pp. 83-101. TORRECILLA GORBEA, M. J. e IZARZUGAZA LIZARRAGA, I., "Evolución urbana del primer Bilbao: las siete Calles y sus elementos más sobresalientes", en GONZÁLEZ CEMBELLÍN, J. M. y ORTEGA BERRUGUETE, A. R. (eds.), Bilbao, arte e historia, I. Bilbao, Diputación Foral de Vizcaya, Departamento de Cultura, 1990, pp. 50-52. PLAZAOLA, J.: Historia del Arte Vasco, II. De Gótico al Renacimiento. Lasarte-Oria, Etor Ostoa, 2002, pp. 259-260.

7 VVAA: "Iglesia de San Salvador en Guetaria", en MUÑOZ-BAROJA PEÑAGARICANO, J. (coord.), Monumentos Nacionales de Euskadi, tomo II.... op. cit., pp. 223-23. PLAZAOLA, J: op. cit., pp. 259-260.

8 MURUGARREN, L.: op, cit., pp. 17-18.

9 Archivo General de Simancas [AGS], MPD, 08,001. Dicho plano puede consultarse en: http://www. $\mathrm{mcu}$.es/ccbae/es/consulta/registro.cmd?id=179069 [consultado el 16/10/2018]

10 GÓMEZ PIÑEIRO, J. y SÁENZ GARCÍA, J. A.: Documentos cartográficos históricos de Guipuzkoa, II Servicio Histórico Militar. Donostia, Diputación Foral de Guipuzkoa, 1999, pp. 116-117. terminación de la calle 31 de Agosto, anteriormente llamada de la Trinidad, lo que explica que la entrada principal estuviese dispuesta en el lateral sur del templo, flanqueada por una torre cuadrada rematada por un campanario.

En esta iglesia parroquial de Santa María quisieron fundar y edificar una capilla con uso funerario Alonso de Idiáquez y su mujer Gracia de Olazábal, quienes desde 1538 residían en la localidad, donde habían contraído matrimonio ${ }^{11}$. Este noble tolosano fue uno de los militares y políticos guipuzcoanos más relevantes al servicio de la corona española en estos momentos, comendador de la orden de Santiago y secretario del monarca Carlos I, al que el humanista Luis Vives le dedicó su obra De conscribendis epistolis (1534) ${ }^{12}$.

Idiáquez y su esposa obtuvieron el 21 de diciembre de 1539 del regimiento de la localidad la correspondiente licencia para adquirir en el templo una capilla de patronato próxima al altar mayor por el lateral izquierdo, la de San Mateo, tal y como estaba construida, que lindaba y comunicaba con la de San Pedro, quedando ésta a la par de la capilla mayor del templo por el lado del evangelio ${ }^{13}$. Concretamente, les fue cedida parte de la capilla de San Mateo, desde la puerta de acceso a la misma hasta el altar de dicha dependencia, dejando libre el solar ocupado en su interior por tres sepulturas pertenecientes a las casas de Î́ñigo Ortiz de Salazar, del bachiller Martín Ruiz y de Pedro Martínez de Igueldo, los cuáles seguirían disfrutando de su posesión y patronato. Sobre la fábrica de la capilla de San Mateo, los Idiáquez construirían una nueva bajo la titularidad de la Concepción de María, pudiendo aumentar su planta 35 pies de ancho hacia el norte, lindante con la atalaya y 50 pies de largo hacia el este, en dirección a la Zurriola, donde se emplazaba la casa del vicario, ocupando parte del suelo del cementerio existente en este espacio.

1 AZCONA, T. DE: Fundación y construcción de San Telmo de San Sebastián: estudio y documentos. Sa Sebastián, Grupo Doctor Camino de Historia de San Sebastián, 1972, pp. 9-21. AYERBE IRÍBAR, M. R., El Monasterio dominico de San Pedro González Telmo (San Sebastián): de centro religioso a centro cultural y museístico de primer orden de la ciudad. San Sebastián, Kutxa Fundazioa, D.L., 2012, p. 55.

12 PÉREZ-MÍNGUEZ, F.: "Los Idiáquez y el Monasterio de San Telmo de San Sebastián", Boletín de la Real Academia de la Historia, tomo 98, 1931, p. 819. ESCUDERO, J. A.: Los secretarios de Estado y del Despacho (1474-1724), vol. I. Madrid, Instituto de Estudios Administrativos, 1969, pp. 103-104. BARRIOS, F. El Consejo de Estado de lo morqu' españl 1521-1812. Madid, Cons.jo de Etado, 1984, pp. 315-316. 315-316. MORA AFAN, JC. “Alono de Idlakez (197-1547). De Cristegias de poder en la primera mitad del Quinientos", Boletín de estudios históricos sobre San Sebastián, n. ${ }^{\circ} 43$ 2010, pp. 43-84

13 Archivo Histórico Provincial de Zaragoza [AHPZ], P/1519/7. Apéndice Documental n.ำ 1 . 
De igual modo, con objeto de edificar la nueva capilla de mayores dimensiones, se le otorgó a este noble matrimonio tolosano el correspondiente permiso para derribar la muralla de la villa lindante con las paredes de la capilla de San Mateo y San Pedro, si bien Idiáquez quedó obligado a construir una nueva puerta en el muro defensivo junto a la iglesia, como la existente, por la que los vecinos de la localidad pudiesen salir hacia el camino que llevaba al castillo emplazado en la Mota. Asimismo, podrían derribar el muro exterior de la capilla de San Sebastián, ubicada en el claustro y lindante con la capilla de San Mateo, y añadir dicho espacio a la nueva dependencia que estos nobles pretendían fabricar, reservando la posesión de las sepulturas que algunos particulares tenían en la misma. En definitiva, eliminar las paredes existentes entre las capillas de San Mateo, San Pedro y el altar mayor "y hacer en ellos los arcos, ventanas y hedificios que quisieren y fueren necesario y poner en las dichas murallas de entre las dichas capillas rexas de fierro y lo que mas quisieren para que puedan tener y tengan vista desde la dicha su capilla que asi a de hacerse a la dicha capilla y altar maior de la dicha iglesia, para oyr y ver los oficios divinos que en ella se celebraren libremente sin impedimento alguno". Los Idiáquez se comprometieron a comenzar la construcción de la nueva capilla en un plazo de tres años y a terminarla en los diez siguientes, dotándola con 100.000 maravedíes de renta perpetua, espacio sagrado que sería atendido por capellanes oriundos de la localidad.

La concesión de las capillas de San Mateo y San Sebastián a los Idiáquez también fue ratificada unos días más tarde, el 24 de diciembre de 1539, por el cabildo eclesiástico, reunido en la casa de Martín de Lusando, vicario de Santa María ${ }^{14}$. Sin embargo, Alonso de Idiáquez y su esposa no quedaron conformes con la entrega de dichas dependencias, ya que consideraban que el emplazamiento era estrecho y estaba alejado del altar mayor y ellos pretendían erigir una capilla grande y suntuosa. Por ello, en esta misma reunión solicitaron al regimiento de la villa la cesión de la capilla de San Pedro para unirla a la de San Mateo y San Sebastián, a lo que accedió aquel, donándoles todo el ancho de la dependencia desde las escaleras existentes en la misma hacia atrás, sin incluir la zona de la cabecera, quitando además el altar del santo titular de la cofradía de San Pedro ${ }^{15}$, que sería traslado a la capilla de San Juan, adosada al altar mayor por el lateral de la epístola.

14 AHPZ, P/1519/7.

15 Sobre esta cofradía, véase IMÍZCOZ, J. M.: op. cit. pp. 168-169.
Unos meses más tarde, el 11 de octubre de 1540, el cabildo eclesiástico, reunido en la capilla de Santa Catalina ubicada en el claustro de la iglesia de Santa María, confirmó la donación de la referida capilla de San Pedro a los Idiáquez, aprovechando la visita pastoral del obispo Pedro Pacheco, sin cuyo permiso no se podían modificar los altares. Así, el prelado pamplonés concedió el 16 del presente mes la licencia para llevar el altar de San Pedro a la capilla de San Juan Bautista, en la que los cofrades de San Pedro celebrarían a partir de ahora sus ceremonias religiosas, y para quitar el altar e imagen de San Mateo y San Miguel existentes en la capilla de San Mateo y disponerlas en el lugar del templo que el vicario Lusando considerase más oportuno ${ }^{16}$.

Sin embargo, el proyecto edilicio de Alonso de Idiáquez y Gracia de Olazábal de construir una capilla de patronato en la iglesia de Santa María de San Sebastián finalmente no se materializó, ya que antes de que concluyesen los tres años de plazo estipulados en el acuerdo de diciembre 1539 para iniciar la construcción de dicha dependencia, rescindieron el contrato. El noble matrimonio obtuvo en junio de 1541 el permiso oportuno del obispo de Pamplona para conmutar la construcción de la referida capilla por la edificación de un convento de dominicos y colegio de Sagrada Escritura en la villa ${ }^{17}$, decisión que secundaron en septiembre del mismo año los patronos civiles y eclesiásticos del templo donostiarra, revocando las escrituras de cesión otorgadas anteriormente ${ }^{18}$.

De este modo, Alonso de Idiáquez y Gracia de Olazábal obtuvieron el patronato del nuevo convento de San Telmo que la orden de predicadores quería construir en la villa donostiarra. Una empresa edilicia que estos nobles se ofrecieron a financiar, firmando un primer acuerdo el 15 de mayo de 1541, reservándose el derecho de enterramiento en la capilla mayor del templo para sí y sus familiares ${ }^{19}$, en la que construirían una tribuna pétrea desde la que poder seguir la celebración de los divinos oficios ${ }^{20}$. Cláusulas fundacionales que fueron tenidas en cuenta en la traza que diseñó en 1542 fray Martín de Santiago para

6 AHPZ, P/1519/7. Una copia de los contratos y aprobación de las capillas cedidas a los Idiáquez se conserva en AHPZ, P/1519/6

17 AHPZ, P/1519/7.

18 AHPZ, P/1519/9. AHPZ, P/1519/10.

19 El 29 de marzo de 1543 el Papa Paulo III expidió una bula en Bolonia por la que concedió a Gracia de Olazábal y su marido el correspondiente permiso para trasladar los restos mortales de sus antecesores enterrados en la sepultura que poseían en la parroquia de Santa María de San Sebastián al nuevo sepelio del monasterio de San Telmo. AHPZ, P/1519/14.

20 AHPZ, P/1519/1, ff. 15v-19v; P/1519/8; P/1520/1 
construir el convento ${ }^{21}$ y que finalmente fueron cumplidas, haciendo de la cabecera de la iglesia del convento dominico una capilla de patronato y panteón del distinguido linaje de los Idiáquez ${ }^{22}$. Una capilla funeraria privilegiada en la que se dispuso el sepulcro de mármol blanco de los fundadores realizado por Taddeo Carlone en Génova por encargo de su hijo Juan en 1577, espacio que en el último tercio del siglo XVI fue ornamentado con pinturas murales manieristas que acometieron pintores italianos vinculados al exorno pictórico del monasterio del Escorial ${ }^{23}$ (fig. 3).

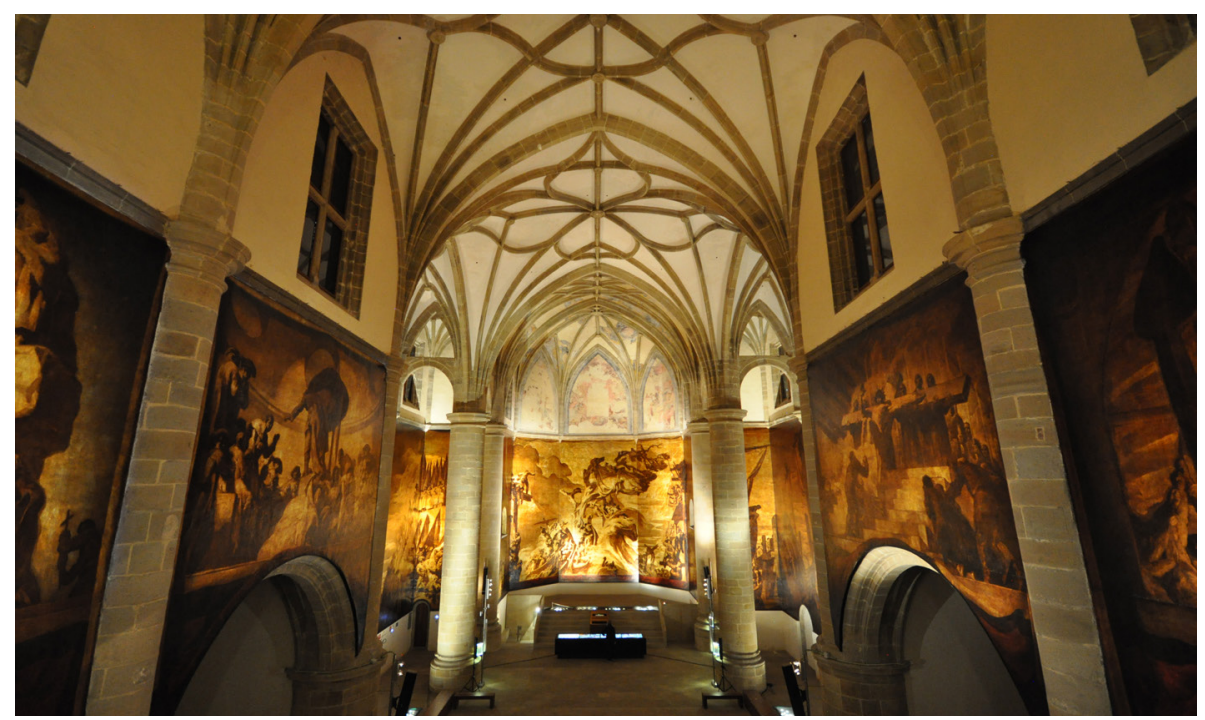

Fig. 3: Interior de la iglesia del convento de San Telmo de San Sebastián

21 AHPZ, MPGD/000194. TARIFA CASTILLA, M. J., "Algunas curiosidades y cosas no necesarias y superfluas: la traza de fray Martín de Santiago para el convento de San Telmo de San Sebastián”, en XXI Congreso Nacional de Historia del Arte: Vestir la arquitectura, Burgos, 2018 [en prensa].

22 Véase al respecto, AZCONA, T. DE: Fundación y construcción de San Telmo de San Sebastián..., op. cit. AYERBE IRÍBAR, M. R., op. cit., pp. 66-68. FORNELLS, M.: "La iglesia de San Telmo", en Los lienzos de José María Sert en la iglesia de San Telmo de Donostia-San Sebastián. San Sebastián, Asociación de Amigos del Museo de San Telmo, 2006, pp. 21-47.

23 ECHEVERRÍA GOÑI, P. L.: El Renacimiento oculto en la iglesia de San Telmo de San Sebastián. La capilla-panteón escurialense de los Idiáquez y sus pinturas (1574-1614). San Sebastián, San Telmo Museoa 2017, pp. 51-74.
No obstante, los miembros de la casa de Idiáquez-Olazábal siguieron poseyendo una serie de sepulturas en la iglesia parroquial de Santa María, algunas de ellas ubicadas en la capilla de San Sebastián emplazada en el claustro, como confirmó el obispo pamplonés Diego Ramírez Sedeño de Fuenleal en junio de 1568 en su visita a Tolosa ${ }^{24}$. Dependencia en la que Gracia de Olazábal fundó una capellanía en 1571, cuyo patronato siguió ostentando por herencia familiar a mediados del siglo XVII la duquesa de Ciudad Real ${ }^{25}$.

\section{LA TRAZA DE LA IGLESIA DE SANTA MARÍA DE SAN SEBASTIÁN DE 1539}

Entre los papeles de la casa de Idiáquez, integrados más tarde en los del ducado de Híjar y conservados en la actualidad en el Archivo Histórico Provincial de Zaragoza, se encuentra un plano inédito que reproduce la planta de la iglesia medieval tardogótica de Santa María de San Sebastián existente en 1539 (fig. 4) ${ }^{26}$, tal y como recoge la anotación escrita en el reverso: "Traça de la iglesia de Santa Maria". Este diseño gráfico fue realizado ad hoc con objeto de señalar el lugar en el que se dispondría la capilla de nueva planta que Alonso de Idiáquez y su esposa Gracia de Olazábal querían construir en dicho templo donostiarra. Por ello, proporciona más información de las capillas y edificaciones lindantes a la dependencia que los Idiáquez pretendían acometer, incluso con referencia a sus medidas, frente a lo que sucede con el resto de las partes de la iglesia y el claustro anejo, de los que únicamente se delinea su planta, en algunos casos empleando regla y compás, mientras que otros trazos son realizados a mano alzada, sin precisión a la hora de plasmar de manera proporcionada cada espacio, careciendo de una escala de medición en la proyección del edificio.

A pesar de ello, la anónima traza, dibujada sobre un pergamino con tinta sepia, de 89 centímetros de alto por 57 centímetros de ancho, es sumamente interesante, ya que reproduce la iglesia gótica de Santa María de la que a día de hoy se sabe muy poco. Un templo de tres naves, mayor la central que las laterales, de cinco tramos cada una, sustentados por pilares circulares en el espacio central y por medias columnas en los muros perimetrales, en correspondencia con los contrafuertes adosados al exterior. En el cuarto tramo de la nave central, comenzando a contar por la zona de los pies, se localizaban los asientos de las 


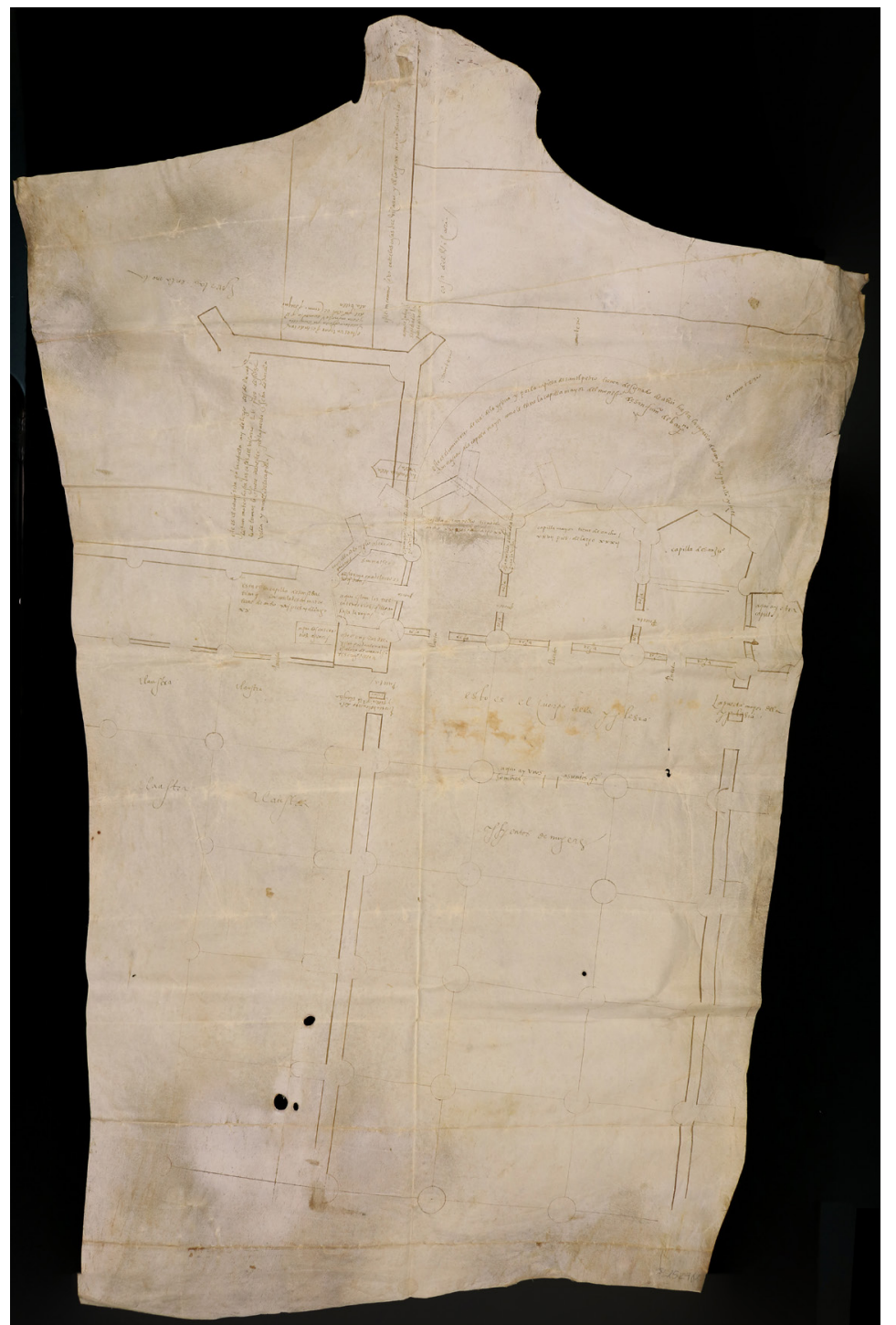

Fig. 4: Planta de la iglesia de Santa María de San Sebastián. 1539. Archivo Histórico Pro vincial de Zaragoza, MPGD/000226. [http://dara.aragon.es/opac/app/item/ahpz?vm=nv\&o$\mathrm{b}=\mathrm{os}: 1 \& \mathrm{q}=000226 \& \mathrm{p}=0 \& \mathrm{i}=1048808]$ mujeres, mientras que el espacio precedente estaba destinado a los hombres, como refieren las correspondientes inscripciones. Sitiales que heredaban las familias de forma directa con gran orgullo y por cuya posesión pleiteaban ante los tribunales eclesiásticos ${ }^{27}$.

Al espacio de las naves dibujado en la traza sucede la cabecera, conformada por una capilla mayor poligonal de cinco lados, a la que se adosan otras dos capillas absidiales más pequeñas, que describen en planta un pentágono de lados rectos, la de San Pedro a la izquierda y la de San Juan en el lateral de la epístola, reforzadas las dos primeras por contrafuertes dispuestos en diagonal. Esta cabecera estaba separada del cuerpo de la iglesia por una reja con sus correspondientes puertas de acceso al presbiterio y capillas laterales, quedando a su vez el altar mayor independizado de las capillas de San Pedro y San Juan por otras verjas. Según las anotaciones escritas en la planta, la capilla mayor medía 27 pies de ancho y 32 de largo y la capilla de San Pedro 20 pies de ancho y 25 de largo. En cambio, de la capilla de San Juan no se dan dimensiones, si bien presenta en planta la misma forma que la de San Pedro, quedando precedida de tres líneas horizontales que probablemente sugieren en el dibujo la existencia de unos escalones, a partir de los cuales se dispone otra capilla adosada al muro perimetral meridional del templo, como indica la anotación "aqui ay otra capilla" (fig. 5).

La puerta principal de acceso a la iglesia se localizaba en la nave meridional, en el tramo más próximo a la cabecera, frontera con la puerta de entrada al claustro, espacio éste adosado al muro septentrional de la nave del evangelio e identificado con la inscripción "claustra", sustentado por pilares cilíndricos similares a los existentes en el templo, aunque de dimensiones menores. En la galería este del claustro se ubicaba la capilla de San Sebastián,

27 En 1529 María Ortiz de Unceta y María Gómez de Olazábal se disputaban un asiento en la iglesia de Santa María localizado en el lateral de la epístola. AHPZ, P/ 1519/3. Juanes de Aramburu, boticario de San Sebastián, declaraba en 1549 que su madre había poseído durante más de 30 años "un asiento de mujeres y sepultura" en la iglesia de Santa María, que ahora usaba su esposa Catalina de Goizueta, el cual intentaba arrebatárselo María Pérez de Verio. Archivo Diocesano de Pamplona [ADP], Secr. Ciordia, c/ 46- n.ํ 2. En 1562 María Gómez de Engómez pleiteaba ante los tribunales eclesiásticos del obispado de Pamplona la posesión de un asiento de mujer en la parroquial de Santa María que había pertenecido a su madre que lindaba a los lados con el de Pascuala de Engómez y Catalina de Erdoa y pert por decín y Bárbara de Hernialde. ADP, Secr. Ibarrola, c/58- n. 6. Asimismo, en 1569 Maria Juan de Acar, vecina de San Sebastián, declaraba poseer "un asiento de mujer de derecho de asentar y ofrecer del dentro de la iglesia parroquial de Santa María". ADP, Secr. Ciordia, c/ 49- n. ${ }^{\circ} 18$ 


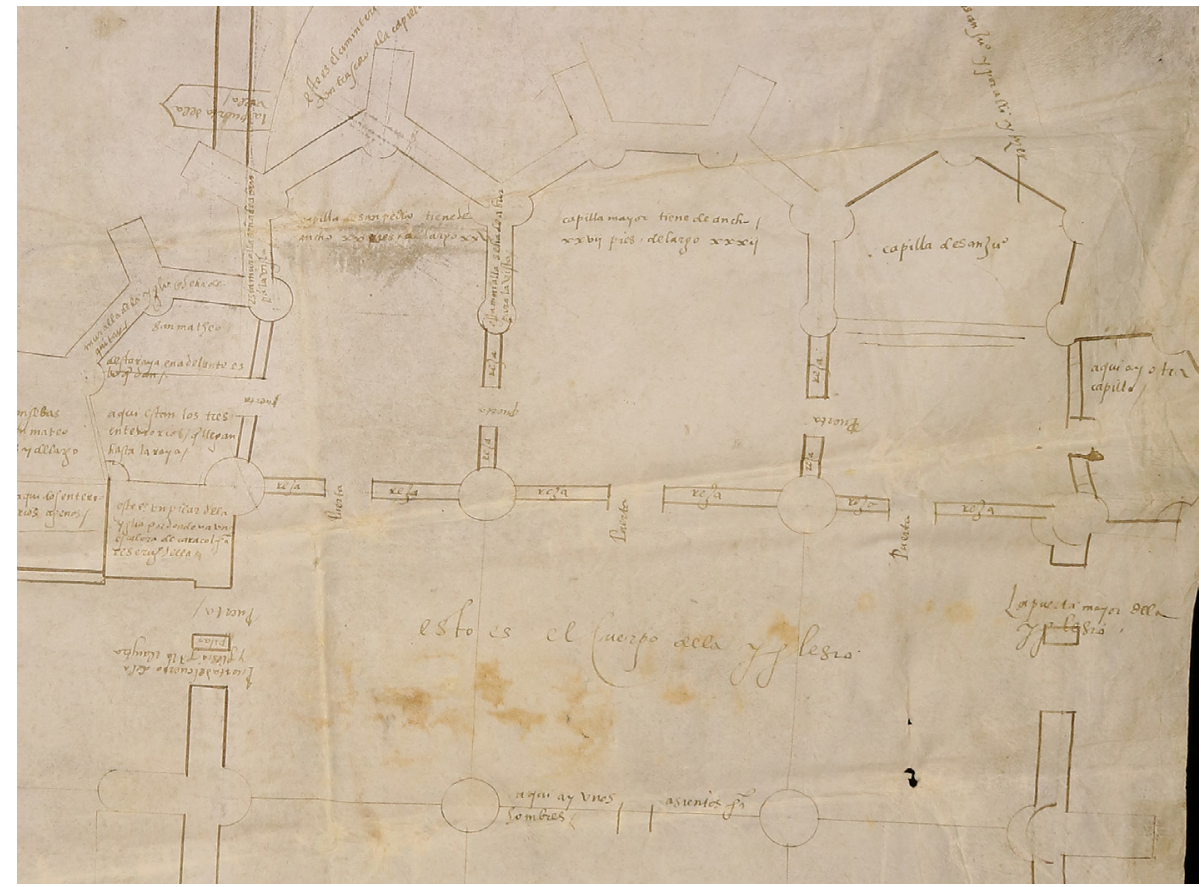

Fig. 5: Planta de la iglesia de Santa María de San Sebastián. 1539. Detalle de la cabecera y parte delantera. Archivo Histórico Provincial de Zaragoza, MPGD/000226. [http://dara.aragon.es/opac/app/item/ahpz?vm=nv\&ob=os:1\&$\mathrm{q}=000226 \& \mathrm{p}=0$ \& $\mathrm{i}=1048808$ ]

que limitaba con la de San Mateo, la cual a su vez estaba adosada a la capilla de San Pedro. Gracias a la consulta de la documentación que acompaña esta traza analizada en el epígrafe precedente ${ }^{28}$, sabemos que dichas dependencias claustrales, tanto la de San Sebastián como la de San Mateo, fueron cedidas por el regimiento de la ciudad y cabildo eclesiástico a Alonso de Idiáquez y su esposa Gracia de Olazábal en diciembre de 1539 con objeto de alargar y ensanchar hacia la atalaya la nueva capilla que este matrimonio quería erigir en el templo bajo la titularidad de la Concepción, motivo por el cual se especifican sus medidas, informando que ambas dependencias juntas ocupaban 26 pies de ancho y 20 de largo.
En el caso de la capilla de San Mateo, se les cedía la parte delantera de esta dependencia desde el altar hasta la puerta de acceso a ella, que comunicaba con la capilla de San Pedro, indicando en la planta con una línea "desta raya en adelante es lo que dan", quedando tras ella tres sepulturas lindantes con un pilar desde el que arrancaba una escalera de caracol para servicio de la iglesia, tumbas que, según se ha referido anteriormente, pertenecían a las familias de Iñigo Ortiz de Salazar, del bachiller Martín Ruiz y de Pedro Martínez de Igueldo, los cuáles seguirían disfrutando de las mismas, al igual que ocurriría con los dueños de los dos enterramientos existentes en la capilla de San Sebastián (fig. 6).

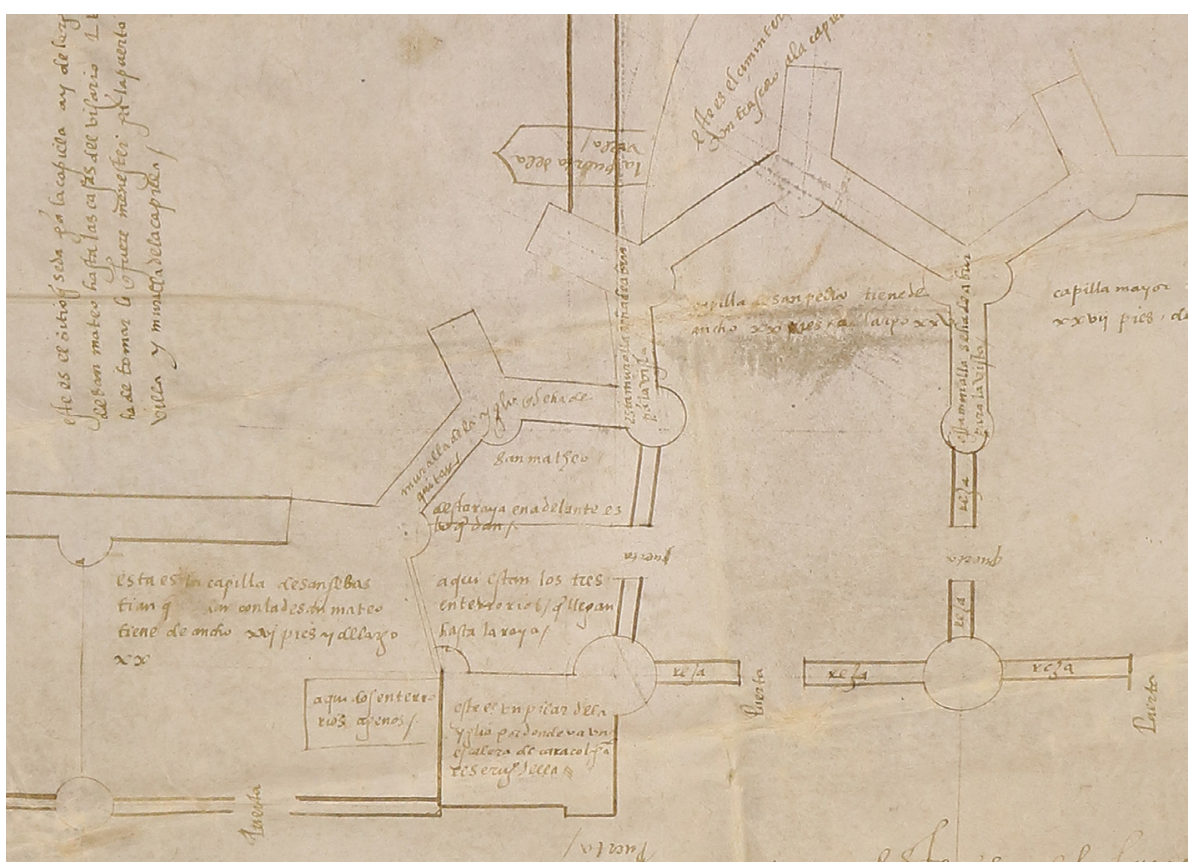

Fig. 6: Planta de la iglesia de Santa María de San Sebastián. 1539. Detalle de las capillas de San Pedro, San Mateo y San Sebastián. Archivo Histórico Provincial de Zaragoza, MPGD/000226. [http://dara.aragon.es/opac/app/item/ hpz?vm=nv\&ob=os: $1 \& \mathrm{q}=000226 \& \mathrm{p}=0 \& \mathrm{i}=1048808$ 
En la escritura de cesión de las capillas de San Mateo y San Sebastián a los Idiáquez, también se le otorgó al secretario del rey la facultad de demoler la muralla defensiva de la localidad lindante con dichas dependencias, anotándose en la planta en la pared exterior de San Mateo "muralla de la yglesia que se ha de quitar", a condición de que el militar tolosano construyese una nueva puerta en el lienzo murario junto al templo por la que los donostiarras pudiesen salir hacia el camino que llevaba a la montaña o Mota, accesos que se dibujan en el plano.

En la traza también se recoge otra de las solicitudes realizada por parte del noble matri monio en el mismo mes de diciembre de 1539 y que asimismo fue atendida por parte de los patronos civiles y eclesiásticos del templo de Santa María, como fue la transmisión de la capilla de San Pedro para unirla a las de San Mateo y San Sebastián, con objeto de que la nueva dependencia que pretendían construir no estuviese alejada del altar mayor, tal y como se escribió en la traza en el muro de la capilla de San Pedro lindante con la capilla de San Mateo "esta muralla se a de abrir para la vista", donación que fue ratificada por el obispo pamplonés en octubre de 1540 .

Al muro norte de la capilla de San Pedro se adosaría la nueva capilla proyectada para los Idiáquez, de grandes dimensiones, delineada con el grosor de los lienzos murales en sus flancos sur y norte, conformando una planta cuadrangular reforzada en las esquinas exteriores por contrafuertes dispuestos en diagonal, en cuyo espacio interior se anotó: "este es el sitio que se da pa la capilla, ay de largo desde la capilla de San Mateo hasta las casas del vicario LV pies, desto se ha de tomar lo que fuera menester pa la puerta que se ha de dar a la villa y muralla de la capilla".

Esta dependencia de uso privativo para los Idiáquez lindaría con el cementerio existente tras la cabecera del templo, señalándose el lugar en el que podría construirse la puerta de la villa, espacio de uso funerario en el que también se emplazaba la casa del vicario de la iglesia de Santa María, una edificación alargada que había sido construida en la década de 1520 por el licenciado Pérez de Lusando con su propio dinero, quien ejercía en aquel momento el cargo vicarial del templo, y que en su testamento fechado en 1543 legó como morada de los sucesivos eclesiásticos que estuviesen al frente de la iglesia, tal y como sucedió tras su fallecimiento en $1546^{29}$. El acceso a dicha vivienda únicamente se podía realizar a travé

29 En una de las cláusulas del codicilo, el licenciado Lusando expresó: "Yten digo que la casa donde bibo moro que junto al cimeterio de la dicha yglesia, yo de mis propios dinerosy azienda la difique pra

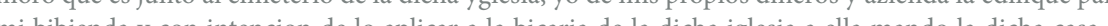
mi bibienda y con intencion de lo aplicar a la bicaria de la dicha iglesia a ella mando la dicha casa a bicario o bicarios que despues de mi de la dicha yglesia de Señora Santa Maria para que puedan bib e biban en ella en toda su bida, uno en pos de otro como sucediese". ADP, Secr. Garro, c/ 127- n. ${ }^{\circ} 1$. del campo santo, en el que se emplazaba la escalera pétrea y puerta principal de la casa, que contaba con bodega y dos pisos de altura. En la traza se dibuja otro inmueble adosado al domicilio del vicario, sin identificar, si bien gracias a la documentación consultada en los archivos revelamos que se trata de la casa de Miguel de Gorosquieta, que no distaba mucho de la herrería en la que trabajaba dedicado al oficio de puñalero ${ }^{30}$.

Según se aprecia en el plano, frente a este edificio discurría la calle que llevaba hasta "el lagar hazia Zurriola", como indica la inscripción "este es un lagar que esta detras del sitio que se da pa la capilla [de los Idiáquez] y sera menester tomar la parte del para acer el camino por aqui a la villa", almacén que lindaba al otro lado con las huertas de la Mota.

Finalmente, esta traza con la planta de la iglesia gótica de Santa María también es sumamente reveladora por otra cuestión, ya que no solo permite conocer el aspecto que presentaba el templo hacia 1539, sino incluso la ampliación que se pretendía acometer en el mismo por la parte absidal. Así, desde el extremo norte de la capilla de San Pedro se traza sobre el espacio ocupado por el cementerio una fina línea curva que termina en el latera opuesto de la capilla de San Juan, un semicírculo delineado tras la cabecera existente en el que se anotó la siguiente inscripción: "este es el çimiterio detras de la yglesia y por la capilla de San Pedro tienen designado de abrir hasta la capilla de San Juan y por alli y hazer un trascoro a la capilla mayor como le tiene la capilla mayor del monesterio de San Francisco de Barcna”. Este convento barcelonés gótico desapareció en el siglo XIX ${ }^{31}$, pero gracias a las noticias que refiere Barraquer y Roviralta, se sabe que la única nave del templo terminaba en un presbiterio presidido por el retablo mayor y "por los costados de él, hasta darle vuelta por su detrás, introducíase un paso o deambulatorio, provisto de capillas radiales en el lado exterior"32, tal y como refiere la anotación de la traza de Santa María. Por tanto, una inscripción que preludia la ampliación que posteriormente sufrió la iglesia donostiarra por la zona de la cabecera a partir de 1566, pero no con un "trascoro", sino con una solución diferente, como se refiere a continuación.

30 ADP, Secr. Garro, c/ 127- n. ${ }^{\circ} 1$

31 Sobre el convento de San Francisco de Barcelona, véase GINÉ I TORRES, A. M.: "El convent de Sant Francesc de Barcelona. Reconstrucció hipotètica”, Acta historica et archaeologica mediaevalia, n. ${ }^{\circ} 9$ 1988, pp. 221-241. CONEJO DA PENA, A. "El convent de Sant Francesc de Barcelona", en PLADEVALL I FONT, A. (dir.), Lart Barcelona, Enciclopèdia Catalana, 2002, pp. 180-182

32 BARRAQUER Y ROVIRALTA, C.: Las casas de religiosos en Cataluña durante el primer tercio del siglo XIX, vol. I. Barcelona, Imprenta de Francisco J. Altés y Alabart, 1906, p. 436. 


\section{NUEVAS NOTICIAS SOBRE LA AMPLIACIÓN DEL TEMPLO GÓTICO} DE SANTA MARÍA EN EL ÚLTIMO TERCIO DEL SIGLO XVI

El edificio gótico de la iglesia donostiarra de Santa María fue ampliado en la segunda mitad del siglo XVI por la parte delantera con objeto de dar cabida a una creciente feligresía, según dio a conocer Azcona en un artículo publicado hace unos años ${ }^{33}$. Una obra que fue acometida de acuerdo a la traza facilitada por el maestro Juan López de Lizarazu ${ }^{34}$, quien estuvo al frente de la misma desde fines de la década de 1560 hasta mediados de la siguiente, cuando le sorprendió la muerte, ocupándose fundamentalmente de los trabajos de cimentación en los que se emplearon 5.000 ducados, financiación que corrió a cargo del regimiento de la villa que ostentaba el "patronato mere lego". La construcción fue continuada por los maestros Juan de Anzara, vecino de Amasa, y Nicolás de Lizarraga, residente en Asteasu, quienes en 1577 se comprometieron a concluirla en ocho años y medio $^{35}$.

El hallazgo de noticias inéditas localizadas en la sección de pleitos del Archivo Diocesano de Pamplona permiten completar la información existente hasta el momento referente a esta fase de engrandecimiento del templo a partir de la cabecera. Así, el 6 de diciembre de 1576 los referidos maestros de cantería Nicolás de Lizarraga ${ }^{36}$ y Juan de Anzara o Anzarobe ${ }^{37}$ se concertaron con la villa de San Sebastián para fabricar la capilla principal de la iglesia de Santa María. Tras el fallecimiento de Aranzobe, Lizarraga continuó la construcción en solitario hasta el 16 de mayo de 1593, cuando renunció a la misma dada su avanzada edad y su indisposición por enfermedad, percibiendo en los años próximos lo que se le adeudaba por el trabajo realizado, así como la cuantía correspondiente a la piedra que

33 AZCONA, T. DE: "Ampliación de la parroquia de Santa María en el siglo XVI", Boletín de estudios históricos sobre San Sebastián, n. 9, 1975 pp. 51- 69.

34 Juan de Lizarazu también dio su parecer en 1573 sobre cómo continuar la ampliación de la iglesia de Santa María de Segura, que en aquel momento se encontraba en obras. ARRAZOLA ECHEVERRÍA, M. A.: El Renacimiento en Guipúzcoa, I, Arquitectura. San Sebastián, Diputación Foral de Guipúzcoa 1988, p. 199.

35 TELLECHEA IDÍGORAS, J. I.: "Sobre la parroquia de Santa María. Dos documentos del fondo Vargas Ponce”, Boletín de estudios históricos sobre San Sebastián, n. ${ }^{\circ}$ 7, 1973, pp. 303-311.

36 Este cantero guipuzcoano proporcionó en 1584 la traza para acometer la torre de la iglesia de San Esteban de Oiartzun. ARRAZOLA ECHEVERRÍA, M. A.: op. cit., p. 163.

37 En 1571 está documentado supervisando las obras de la iglesia de Nuestra Señora de la Asunción de Errenteria. ARRAZOLA ECHEVERRÍA, M. A.: op. cit., p. 129 tenía labrada y sacada del monte Igeldo ${ }^{38}$. La supervisión de la empresa edilicia acometida por Lizarraga corrió a cargo del padre fray Miguel de Aramburu y el maestro Pedro de Mendiola, vecino de Errezil, de parte de la villa, mientras que en nombre del cantero actuaron los maestros Martín de Lizarraga y Francisco de Nagusia, los cuáles discreparon en sus valoraciones, siendo nombrado de común acuerdo como tercero Miguel de Altuna veedor de obras eclesiásticas del obispado de Pamplona ${ }^{39}$, quien estimó la fábrica en más de 12.000 ducados $^{40}$. Para el mes de diciembre del presente año de 1593 Lizarraga ya había fallecido, habiendo recibido hasta el momento 11.401 ducados por sus jornales. En los años próximos su viuda, María Juan de Larrumbide, avecindada en Asteasu, continuó cobrando los dineros correspondientes al trabajo realizado por su difunto esposo en "ciertos paños y paredes de cal y canto y ciertas capillas de la dicha yglesia por mandado del concejo, alcaldes, jurados y regimiento", como reclamó en 1602 ante los tribunales eclesiásticos del obispado pamplonés ${ }^{41}$.

Por otro lado, los litigios judiciales en los que se vio envuelto el patronato de la iglesia con motivo de la expropiación de diferentes solares e inmuebles sobre los que erigir la ampliación del templo, como la casa del vicario Pérez de Lusando y la del puñalero Miguel de Gorosquieta, a las que se ha aludido anteriormente, motivaron la paralización y dilatación de la fábrica. En 1589 el actual vicario de la iglesia de Santa María, Juan López de Santiago, inició un pleito ante los tribunales eclesiásticos navarros contra el regimiento de la villa de San Sebastián, recordando que en agosto de 1569 el doctor Alquiza, visitador del obispado pamplonés, en nombre del prelado Diego Ramírez Sedeño de Fuenleal había ordenado entregar la casa del licenciado Pérez de Lusando, ubicada tras la cabecera de la iglesia de Santa María y lindante con la muralla vieja de la localidad y con la residencia del puñalero, para ampliarla por este espacio, si bien el regimiento quedó obligado a proporcionales otra vivienda en la que morar los vicarios de la misma y entre tanto pagarles el alquiler de dicho alojamiento, incumpliendo en dicho convenio ${ }^{42}$. De acuerdo con el mandato del obispo, la construcción de la nueva cabecera había sido comenzada siguiendo la traza que había proporcionado el maestro Juan de Lizarazu, vecino de Villarreal, aprobada por el

38 ADP, Secr. Garro, c/ 196- n. ${ }^{\circ} 8$, ff. 15v-20

Sobre la prolífica labor de este cantero guipuzcoano, vése TARIFA CASTILLA, M. J: "Miguel de Altuna, veedor de obras del obispado de Pamplona (1584-1601)”, Artigrama, n. ${ }^{\circ} 30,2015$, pp. 221-240.

40 ADP, Secr. Garro, c/ 196- n. ${ }^{\circ} 8$, ff. 21 r-21y.

41 ADP, Secr. Garro, c/ 196- n. ${ }^{\circ} 8$

42 ADP, Secr. Garro, c/ 127- n. ${ }^{\circ}$, ff. $1 \mathrm{r}-13$ 
regimiento, el prelado pamplonés, los cabildos eclesiásticos donostiarras y ciertos maestros peritos en el $\operatorname{arte}^{43}$. Sin embargo, la obra se hallaba paralizada en julio de 1570, ya que no se podía continuar con la cimentación de la fábrica hasta que se adquiriese y derrocase la vivienda del referido Miguel de Gorosquieta, como declararon los maestros canteros Martín de Mendiola, Julián de Urrutia y Domingo de Balerdi ${ }^{44}$. El inmueble fue finalmente expropiado tras ser estimado en septiembre de 1571 por Martín de Lasarte y Domingo de Igola, maestros carpinteros y por Juan Pérez de Jáuregui y Domingo de Echeverría maestros canteros, en 314 ducados, recibiendo cada uno de ellos por su labor 4 ducados ${ }^{45}$.

El proyecto edilicio de ampliación del templo de Santa María fue reanudado con fuerza a partir de 1590, cuando por orden del obispo pamplonés las cofradías del Santísimo Sacramento, de la Vera Cruz y de la Misericordia prestaron en 1594 una buena suma de diner ${ }^{46}$. En la fase final de ampliación de la fábrica participó el maestro de obras Pedro de Zaldúa, quedando concluida la edificación para $1610^{47}$.

Esta iglesia, con el cuerpo de naves perteneciente a la época medieval y el engrandecimiento por la zona de la cabecera a partir del último tercio del siglo XVI, es la que fue dibujada en planta en el plano proyectado en 1728 por el ingeniero Juan de Subreville ${ }^{48}$ (fig. 7). Un diseño que reproduce un templo de tres naves, mayor la central que las laterales, de siete tramos, siendo los tres de los pies más anchos, correspondientes a la fábrica medieval, cerradas con bóvedas de crucería simple y articuladas por seis columnas pareadas y otra tantas pilastras, rematándose en un ábside ochavado. Edificio que seguía contando con el claustro de origen medieval, dispuesto al norte y adosado a los cuatro tramos y medio de los pies del templo, con las pandas cubiertas con bóvedas de crucería simple, al que se accedía desde el interior de la iglesia, quedando separado de ésta por una zona o galería de tramos rectangulares (fig. 8). Por su parte, el ingeniero Juan Bernardo de Frosne, también dibujó con gran precisión en el plano que delineó de San Sebastián en 1744 los principales

43 Según refirió uno de los testigos presentados en el pleito en 1570, la población donostiarra había aumentado considerablemente en los últimos anos, por lo que sus feligreses no cabian en la iglesia de Santa María cuando acudían a escuchar los divinos oficios, y que "abiendo tratado muchas bezes en regimiento ensanchar o alargar la dicha yglesia, traxieron maestros e dieron sus traças y la mejor de todas segun se dezia la de maestre Juan de Liçarazu, que despues fue confirmada por el señor obispo $y$ el dicho regimiento". ADP, Secr. Garro, c/ 127- n. o 1, f. 207r

44 ADP, Secr. Garro, c/ 127- n ${ }^{\circ} 1$, ff. 202r-205v.

45 ADP, Secr. Garro, c/ 127- n. ${ }^{\circ} 1$, f. 239 r

46 MURUGARREN, L.: op, cit., p. 20. ADP, Secr. Sojo, c/ 93- n. ${ }^{\circ} 2$.

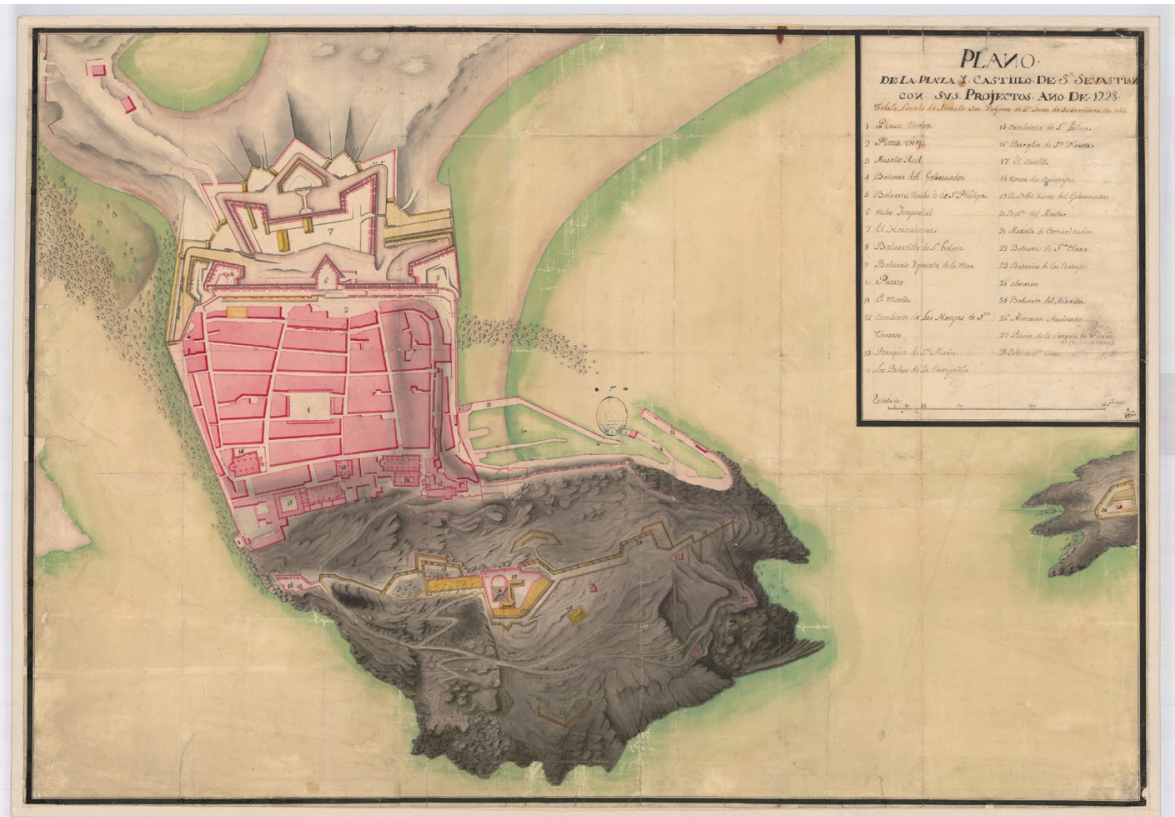

Fig. 7: Plano de San Sebastián de 1728 por Juan de Subreville. Archivo General Militar de Madrid, SS-13/10 Ministerio de Defensa, España. [http://www.ejercito.mde.es/unidades/Madrid/ihycm/Archivos/agm-madrid-index.html]

47 CORTÁZAR Y MACHIMBARRENA, A.: op. cit., p. 11. AZCONA, T. DE: "Ampliación de la parroquia de Santa María ..., op, cit., p. 58.

48 Archivo General Militar de Madrid [AGMM], SS-13/10. IZAGUIRRE, R. DE: op. cit., pp. 300-301 MURUGARREN, L.: op, cit., pp. 20-21. GÓMEZ PIÑEIRO, J. y SÁENZ GARCÍA, J. A.: op. cit., pp. $144-145$. 


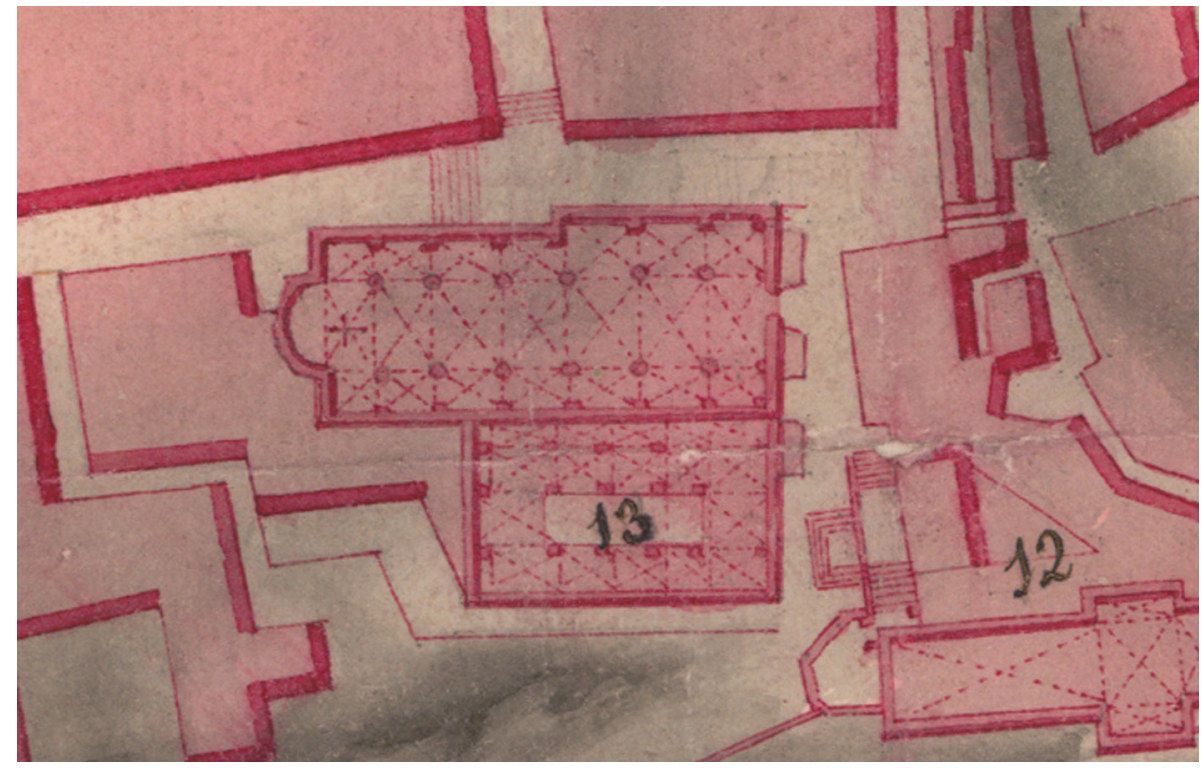

Fig. 8: Plano de San Sebastián de 1728 por Juan de Subreville. Detalle de la planta de la iglesia de Santa María. Archivo General Militar de Madrid, SS-13/10. Ministerio de Defensa, España. [http://www.ejercito.mde.es/unidades/Madrid/ihycm/Archivos/agm-madrid-index.html]

conjuntos arquitectónicos religiosos existentes en la localidad ${ }^{49}$ (fig. 9), entre los que se encontraba la planta de esta iglesia mariana (fig. 10). Un edificio que para 1739 se encontraba en estado ruinoso, por lo que el regimiento de la localidad acordó demolerlo y edificar otra iglesia "con más ensanche y proporción para mayor decencia del culto divino y capacidad de la mucha gente que concurre a ella por ser la principal" ${ }^{50}$, desapareciendo unos años después la fábrica gótico-renacentista sobre la que se erigió el templo barroco que ha llegado hasta nuestros días.

49 Archivo Cartográfico del Centro Geográfico del Ejército, AR. F-T.2-C.1-189.

50 MURUGARREN, L.: op, cit., p. 30 .

ARS BILDUMA, nº 9 (2019), pp. 17-32 • ISSN 1989-9262 • UPV/EHU Press • https://doi.org/10.1387/ars-bilduma.19777

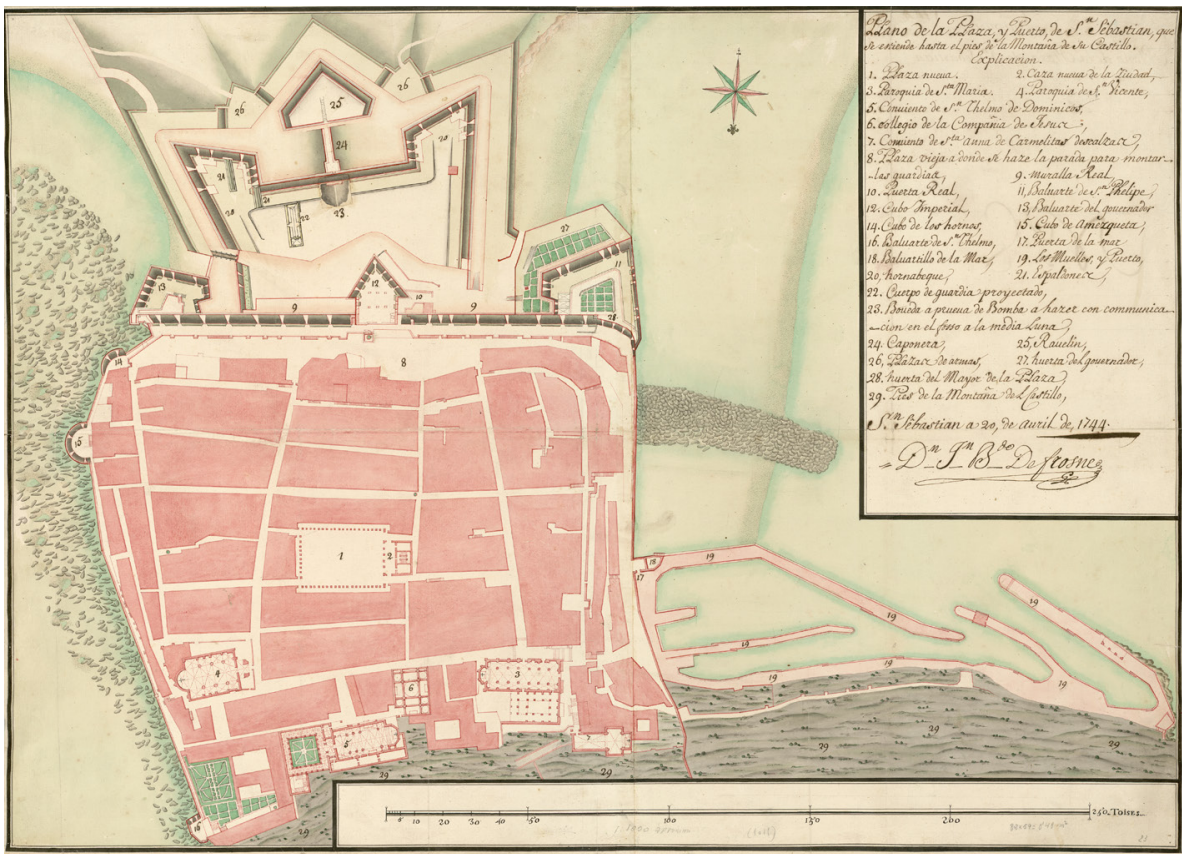

Fig. 9: Plano de San Sebastián de 1744 por Juan Bernardo de Frosne. Archivo Cartográfico del Centro Geográfico del Ejército, AR. F-T.2-C.1_189. Ministerio de Defensa, España. [http://www.ejercito.mde.es/unidades/Madrid/ ceget/cartoteca/index.html]

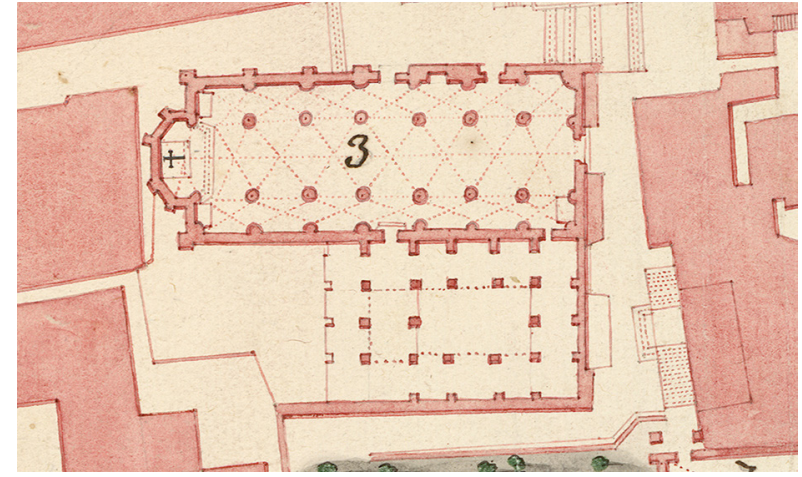

Fig. 10: Plano de San Sebastián de 1744 por Juan Bernardo de Frosne. Detalle de la planta de la iglesia de Santa María. Archivo Cartográfico del Centro Geográfico del Ejército, AR. F-T.2-C.1_189. Ministerio de Defensa, España. [http://www.ejercito.mde.es/unidades/Madrid/ceget/cartoteca/index.html] 


\section{BIBLIOGRAFÍA}

ÁLVAREZ OSES, J. A.: "A propósito de un pleito surgido en la construcción de la Parroquia de Santa María (1775-1756)”, Boletín de estudios históricos sobre San Sebastián, n. o 9, 1975, pp. 185-207.

ARrAZOLA ECHEVERRÍA, M. A.: El Renacimiento en Guipúzcoa, I, Arquitectura. San Sebastián, Diputación Foral de Guipúzcoa, 1988

ASTIAZARÁIN ACHABAL, M. I.: Arquitectos guipuzcoanos del siglo XVIII. Martín de Zaldúa, José de Lizardi, Sebastián de Lecuona. San Sebastián, Diputación Foral de Guipúzcoa, 1988.

ASTIAZARÁIN ACHABAL, M. I.: La iglesia de Santa María de San Sebastián. San Sebastián, Sociedad Guipuzcoana de Ediciones y Publicaciones, 1989.

AYERBE IRÍBAR, M. R., El Monasterio dominico de San Pedro González Telmo (San Sebastián): de centro religioso a centro cultural y museístico de primer orden de la ciudad. San Sebastián, Kutxa Fundazioa, D.L., 2012.

AZCONA, T. DE: "Ampliación de la parroquia de Santa María en el siglo XVI", Boletín de estudios históricos sobre San Sebastián, n. 9 9, 1975, pp. 51- 69.

AZCONA, T. DE: Fundación y construcción de San Telmo de San Sebastián: estudio y documentos. San Sebastián, Grupo Doctor Camino de Historia de San Sebastián, 1972.

AZCONA, T. DE: San Sebastián y la provincia de Guipúzcoa durante la Guerra de las Comunidades (1520-1521): Estudio y documentos. San Sebastián, Grupo Doctor Camino de Historia de San Sebastián, 1974.

BARRAQUER Y ROVIRALTA, C.: Las casas de religiosos en Cataluña durante el primer tercio del siglo XIX, vol. I. Barcelona, Imprenta de Francisco J. Altés y Alabart, 1906

BARRIOS, F.: El Consejo de Estado de la monarquía española 1521-1812. Madrid, Consejo de Estado, 1984

CAMINO Y ORELLA, J.: Historia civil, diplomático, eclesiástica anciana y moderna de la ciudad de San Sebastián, con varias noticias particulares pertenecientes a la provincia de Guipúzcoa. San Sebastián, Ediciones del Ayuntamiento de San Sebastián, 1963.
CONEJO DA PENA, A.: "El convent de Sant Francesc de Barcelona", en PLADEVALL FONT, A. (dir.), L'art gòtic a Catalunya. Arquitectura, I. Catedrals, monestirs i altres edificis religiosos. Barcelona, Enciclopèdia Catalana, 2002, pp. 180-182.

CORMENZANA LIZARRÍBAR, I.: "El arte de la Basílica de Santa María del Coro en San Sebastián”, Boletín de estudios históricos sobre San Sebastián, n. ${ }^{\circ}$ 9, 1975, pp. 271-298.

CORTÁZAR Y MACHIMBARRENA, A.: Monografía de la Iglesia Parroquial de Santa Ma ría, de la ciudad de San Sebastián. San Sebastián, Grupo Dr. Camino de Historia Donostiarra, 1974.

ECHEVERRÍA GOÑI, P. L.: El Renacimiento oculto en la iglesia de San Telmo de San Sebastián. La capilla-panteón escurialense de los Idiáquez y sus pinturas (1574-1614). San Sebastián, San Telmo Museoa, 2017.

ESCUDERO, J. A.: Los secretarios de Estado y del Despacho (1474-1724), vol. I. Madrid, Instituto de Estudios Administrativos, 1969.

FORNELLS, M.: "La iglesia de San Telmo", en Los lienzos de José María Sert en la iglesia de San Telmo de Donostia-San Sebastián. San Sebastián, Asociación de Amigos del Museo de San Telmo, 2006, pp. 21-47.

GINÉ I TORRES, A. M.: "El convent de Sant Francesc de Barcelona. Reconstrucció hipotètica", Acta historica et archaeologica mediaevalia, n. ${ }^{\circ}$ 9, 1988, pp. 221-241.

GÓMEZ PIÑEIRO, J. y SÁENZ GARCÍA, J. A.: Documentos cartográficos históricos de Guipuzkoa, II. Servicio Histórico Militar. Donostia, Diputación Foral de Guipuzkoa, 1999.

GOÑI GAZTAMBIDE, J.: "Diócesis de Pamplona”, Príncipe de Viana, Homenaje a José Goñi Gaztambide, n. ${ }^{\circ}$ 245, 2008, pp. 543-551.

GOÑI GAZTAMBIDE, J.: Historia de los obispos de Pamplona, I. Siglos IV-XIII. Pamplona Eunsa, 1979.

IMÍZCOZ, J. M.: "Hacia nuevos horizontes", en ARTOLA, M. (ed.), Historia de Donostia-San Sebastián. San Sebastián. Editorial Nerea, 2000.

IZAGUIRRE, R. DE: "Las sucesivas edificaciones de Santa María la Mayor", Boletín de estudios históricos sobre San Sebastián, n. ${ }^{\circ}$ 7, 1973. 
MORA AFÁN, J. C.: "Alonso de Idiakez (1497-1547). De Criado a Secretario Real. Estrategias de poder en la primera mitad del Quinientos", Boletín de estudios históricos sobre San Sebastián, n. ${ }^{\circ} 43,2010$, pp. $43-84$

MURUGARREN, L.: Basílica de Santa María. San Sebastián. Su historia, arte y vida. San Sebastián, Caja de Ahorros Municipal, 1973.

PEÑUELAS, J.: "La iglesia de Santa María de San Sebastián”, Boletín de estudios históricos sobre San Sebastián, n. ${ }^{\circ}$ 7, 1973, pp. 291-298.

PÉREZ-MÍNGUEZ, F.: “Los Idiáquez y el Monasterio de San Telmo de San Sebastián”, Boletín de la Real Academia de la Historia, tomo 98, 1931.

PLAZAOLA, J.: Historia del Arte Vasco, II. Del Gótico al Renacimiento. Lasarte-Oria, Etor Ostoa, 2002.

TARIFA CASTILLA, M. J.: "Miguel de Altuna, veedor de obras del obispado de Pamplona (1584-1601)”, Artigrama, n. ${ }^{\circ} 30,2015$, pp. 221-240.

TARIFA CASTILLA, M. J., "La iglesia de San Vicente en San Sebastián: los contratos, trazas y artífices del proyecto edilicio (1507-1548)”, Locus Amoenus, n. ${ }^{\circ}$ 16, 2018, pp. 71-92.

TARIFA CASTILLA, M. J., “Algunas curiosidades y cosas no necesarias y suplerfluas: la traza de fray Martín de Santiago para el convento de San Telmo de San Sebastián”, en XXII Congreso Nacional de Historia del Arte: Vestir la arquitectura, Burgos, 2018 [en prensa].

TELLECHEA IDÍGORAS, J. I.: "Sobre la parroquia de Santa María. Dos documentos del fondo Vargas Ponce”, Boletín de estudios históricos sobre San Sebastián, n. ${ }^{\circ}$ 7, 1973, pp. 303-311.

TORRECILLA GORBEA, M. J. e IZARZUGAZA LIZARRAGA, I., "Evolución urbana del primer Bilbao: las siete Calles y sus elementos más sobresalientes”, en GONZÁLEZ CEMBELLÍN, J. M. y ORTEGA BERRUGUETE, A. R. (eds.), Bilbao, arte e historia, I. Bilbao, Diputación Foral de Vizcaya, Departamento de Cultura, 1990, pp. 50-52.

VVAA: “Iglesia de Santa María en Donostia-San Sebastián”, en MUÑOZ-BAROJA PEÑAGARICANO, J. (coord.), Monumentos Nacionales de Euskadi, tomo II, Guipúzcoa. Vitoria, Gobierno Vasco, Departamento de Cultura, 1985, pp. 91-102.
VVAA: "Iglesia de Santiago en Bilbao", en MUÑOZ-BAROJA PEÑAGARICANO, J (coord.), Monumentos Nacionales de Euskadi, tomo III, Vizcaya. Vitoria, Gobierno Vasco, Departamento de Cultura, 1985, pp. 83-101. 


\section{APÉNDICE DOCUMENTAL}

Documento $n .^{\circ} 1$

San Sebastián, 21 de diciembre de 1539

Escritura de cesión de la capilla de San Mateo de la iglesia de Santa María de San Sebastián a Alonso de Idiáquez y Gracia de Olozábal

Archivo Histórico Provincial de Zaragoza, P/1519/7

En la casa concegill de la noble y leal villa de San Sebastian, a veinte y un dias del mes de diziembre año del nascimiento de nuestro señor Jhesuxrispto de mil quinientos y trenta y nueve años queste dicho dia estando ajuntados en concejo a campana tañida segun uso y costumbre e ordenanças de la dicha villa los nobles señores Juan Lopez de Aguirre y Antonio de Echega alcaldes ordinarios de la dicha villa y Miguel de Arizmendi y Juan Bono de Miramun jurados maiores y Martin Perez de Burbo y Juan de Herauso y Lope Descoriaçu regidores [...] y otros muchos vecinos de la dicha villa [...] parescio presente en el dicho concejo Martin de Segura en nombre del señor comendador Alonso de Idiaquez, secretario del consejo de estado de su magestad y de doña Gracia de Olaçabal su muger y dixo a los dichos señores alcaldes, jurados mayores y regidores y personas particulares que como sabian el dicho secretario Idiaquez avia venido a esta villa donde se avia casado y tomado por compañia a la dicha doña Gracia su muger y por el amor con que el dicho concejo le avia recebido y por otros respectos que a ello le movian queria hacer en la dicha villa su asiento, casa y memoria y con este deseo los dichos secretario y su muger por merced de Dios nuestro señor y porque se le ruegue por las animas de sus padres y madres y antecesores suyos y de sus descendientes y subcesores y por honor, aumento y autoridad de la yglesia mayor de Nuestra Señora desta dicha villa tenian voluntad de dar horden en la fundacion y dotacion de una capilla en ella y que en el nombre del dicho señor Idiaquez y de la dicha doña Gracia su muger pedia y suplicaba a la dicha villa y su regimiento y a ellos en su nombre, diesen y señalasen lugar y sitio conveniente en la dicha yglesia mayor donde se pueda fundar y hedificar la dicha capilla para que fuese suya de los dichos secretario Idiaquez y doña Gracia su muger y de sus descendientes y subcesores para en que quedasen por patronos della perpetuamente en la forma y manera que por su sanctidad fuese instituido y hordenado e dicho lo suso dicho el dicho Martin de Segura se salio del dicho concejo y quedando los dichos alcaldes, jurados, regidores y especiales platicaron largamente todos de conformidad y dixeron que por quanto el dicho señor secretario queria hacer su asiento en esta dicha villa y de estar su merced avezindado en ella, la dicha villa y vecinos della recibian mucha gratia y merced por ser la persona que hera y por el favor que les podia dar en todos sus casos y negocios y por otros muchos y buenos respectos les placia y heran contentos de le complacer al dicho señor secretario y doña Gracia su muger en darle el dicho sitio y asiento de la dicha capilla en la dicha iglesia mayor de Santa Maria, y haziedo y cumpliendo lo suso dicho, todos de conformidad le señalaron y dixeron que hazian gratia y donacion a los dichos señor secretario Idiaquez y doña Gracia de Olaçabal su muger para siempre jamas de la capilla de la invocacion de señor Sant Matheo que es en la dicha yglesia de Santa Maria, que es junto y apegante a la capilla de señor San Pedro questa en par de la capilla maior de la dicha yglesia a la mano hizquierda y a la parte del evangelio de la dicha capilla con el hedificio y de la manera que esta al presente desde la punta del asiento de la puerta de la entrada de la dicha capilla que esta junto y apegante al dicho altar de Sant Matheo por la cabeçera de tres sepulturas que estan en la dicha capilla, que son la una de la casa de Iñigo Hortiz de Salazar y la otra de la casa del bachiller Martin Ruiz y la otra de Pedro Martinez de Ygueldo e quedando las dichas sepulturas esentas y libres para que desde agora sea suya y de sus descendientes y subcesores en su casa para siempre jamas para que tengan el patronazgo y provision de las dichas capellanias y personas que se remataren ynstituyeren para el servicio della que perpetuamente para siempre jamas en la forma y manera que por su santidad fuere concedido e instituido con facultad e autoridad, para que teniendo la dicha capilla desde luego en adelante para siempre jamas puedan hedificar en ella como en cosa suya propia, la qual dicha capilla a de ser de la annuciaction de la Concebcion de Nuestra Señora e para que hedificandola la puedan ensanchar y alargar hazia la sierra de la Atalaya y castillo y hazia la parte de Surriola a la parte de la casa del vicario hasta treynta y cinco pies de anchura y cinquenta de largura a su voluntad y arbitrio libremente sin que en ello ni en parte dello les sea ni pueda ser puesto obstaculo ni impedimento alguno, agora ni en ningun tiempo, a ellos ni a los dichos sus descendientes y subcesores, abriendo para el dicho hedificio las murallas de la dicha yglesia que ay al presente detras y altraves y apegantes de la dicha capilla de Sant Matheo y Sant Pedro para que pueda ensanchar y alargar todo lo suso dicho tomando para esto como dicho es lo que fuere menester del cimiterio que esta destras y en derecho de la esquina de la pared de la dicha capilla de Sant Matheo hazia la dicha casa del vicario rompiendo y quitando para lo suso dicho la muralla de la dicha villa que esta al presente apegante a la dicha yglesia por detras de la dicha capilla de Sant Matheo y hacia la casa del vicario, con quel dicho secretario Idiaquez sea obligado y haya de hazer una puerta para el servicio de la dicha villa como al presente esta junto a la dicha yglesia por la dicha muralla en lugar conveniente para salir por ella a la Mota y termino que dizen detras Santa Maria y dando por la dicha puerta camino competente para el servicio de la dicha Mota y termino, y con que asi mismo pueda abrir la muralla que esta entre la dicha capilla de Sant Matheo y la capilla de Sant Sebastian que esta en la claustra de la dicha yglesia y la muralla que esta de la dicha capilla de Sant Sebastian azia fuera de la iglesia, la qual dicha capilla de Sant Sebastian pueda meter y incorporar en la dicha capilla nueva que asi se hoviere de hazer, la qual necesario es que la den y conceden para lo susodicho con las mesmas condiciones y facultades y de la mesma manera que la capilla de Sant Matheo para que juntando la una con la otra puedan romper y de nuevo 
hedificar la dicha capilla nueva a su voluntad y alvedrio libremente y sin que les sea puesto obstaculo ni impedimento alguno y labren y hedifiquen la dicha capilla con los hedeficio y de la manera que ellos quisieren y por bien tuvieren como cosa suya propia reservando las sepulturas que de algunas personas particulares ay en la dicha capilla de Sant Sebastian, o con que los dueños dellas el dicho señor secretario tenga el contento, a lo qual el dicho concejo interverna a hazer lo que en ello pudiere y asi mesmo con la facultad que el dicho señor secretario y su mujer puedan abrir y abran las murallas questan al presente o se hizieren de nuevo entre la dicha capilla de Sant Matheo y la capilla de Sant Pedro y la dicha capilla de San Pedro y la capilla maior de la dicha yglesia y hacer en ellos los arcos, ventanas $\mathrm{y}$ hedificios que quisieren y fueren necesario y poner en las dichas murallas de entre las dichas capillas rexas de fierro y lo que mas quisieren para que puedan tener y tengan vista desde la dicha su capilla que asi a de hacerse a la dicha capilla y altar maior de la dicha iglesia para oyr y ver los oficios divinos que en ella se celebraren libremente sin impedimento alguno, la qual dicha gracia y donacion del dicho sitio y capilla hizieron al dicho señor secretario y a la dicha doña Gracia su muger para agora y siempre jamas, con esto que agora ni de aqui adelante en ningun tiempo del mundo la dicha villa ni otro alguno por concesion suya ni de otra manera alguna no se pueda labrar y hedificar ningun hedificio de ninguna calidad que sea en la dicha capilla de San Pedro que esta al presente en medio y apegante a la dicha capilla y altar maior de la dicha iglesia y la dicha capilla de Santa $\mathrm{Ma}$ theo, de manera que pudiesen impedir la vista desde la dicha capilla que los dichos secretario y su mujer an de hacer a la dicha capilla y altar maior, salvo que se quede libre y esento con sus arcos o rexas como ordenaren y tengan la dicha vista libre y esenta desde la dicha su capilla de la dicha capilla maior para ver los oficios divinos y con que tengan perpetuamente libre y esenta y abierta la entrada de la dicha su capilla por las puertas que al presente ay desde el cuerpo de la dicha iglesia y capilla maior della por la dicha capilla de Sant Pedro, la qual dicha donacion de la dicha capilla y sitio de suso declara dale hizieron con que para el hedeficio de la dicha capilla y de lo que en el querra hacer tomen todo el cielo a su voluntad libremente de la manera que querran haciendo coro y lo demas que bien visto les fuere, asi mesmo concedieron que si en algun tiempo la dicha capilla maior de la dicha yglesia se reedificare o ensanchare o la dicha yglesia maior se mudare [sic] o se hiziere en otro lugar, siempre la dicha capilla de los dichos secretario Idiaquez y doña Gracia su muger y sus sucesores aya de estar cabe la capilla y altar maior a la parte del evangelio como agora esta y la puedan hedeficar, ensanchar y acrecentar lo que para ello conviniere con las dichas facultades, preminencias y de la manera que arriba esta dicho, lo qual todo dixeron que otorgavan y otorgaron en nombre de la dicha villa, y por ella como los alcaldes, jurados y regidores en uno con los dichos especiales, por si y por todos sus descendientes para siempre jamas con que ante todas las cosas el dicho señor secretario Idiaquez y la dicha doña Gracia su mujer sean obligados y ayan de cumplir lo siguiente:
Primeramente que la dicha capilla ayan de empeçar y empiecen a azer y labrar dentro de tres años primeros siguientes y aquella ayan de acabar dentro de diez años siguientes.

Yten que ayan de dotar y doten la dicha capilla con los prestamos y rentas que de presente tiene para ello de cient mil maravedies arriba concedidos por su sanctidad y anexados perpetuamente y con que no se pueda mudare ni desmembrar de la dicha capilla la dicha doctacion agora ni en ningun tiempo del mundo.

Yten con que el capellan mayor y capellanes y otros ministros que hovieren de servir la dicha capilla y gozar de la dicha renta sean hijos de naturales de la dicha villa de los que gozan y que pueden gozar de los beneficios de la dicha villa.

Yten que todas las oblactiones y ofrendas que se haran por los bibos y defuntos en los dias de ofrecer en la dicha capilla ayan de ser e sean para los beneficiados de las yglesias como son las otras ofrendas que se hacen por los otros defuntos de la dicha villa.

Yten que las misas que se ovieren de decir en las onras publicas que se hizieren en los aniversarios, como enterrorio [sic], novena, trentena, cabo daño y segundo año, se ayan de decir las misas cantadas en aquellos dias en el altar maior de la dicha yglesia y se aya de responder del coro maior con que vaian a darle los responsos a la dicha capilla, y que si mas desto quisieren oficiar otras misas o oficios lo puedan hacer libremente.

Yten que no puedan decir misa cantada en la dicha capilla al tiempo que le dizen las misas cantadas y tercia del pueblo en el altar maior, sino antes o despues como quisieren y quando quisieren a su voluntad [...].

Yten que los capellanes que residiran en la dicha capilla sean obligados de yr a las procesiones y otros autos publicos que fuere la dicha clerezia de la dicha villa.

Ytem que el dicho secretario Idiaquez sea obligado de hacer y hedificar todas las obras de la dicha capilla a su costa e que si para hacer aquella aun tuviere que tomar alguna huerta o tierra o casa de alguna persona particular, lo tal sea a cargo del dicho señor secretario de tener el contento dellos.

Y el dicho señor secretario y la dicha su muger haciendo la obligacion, seguridad y contrato de con las dichas condiciones e que aquellas guardaran en todo [...] 